ВЕСО-РОСТОВЫЕ ПОКАЗАТЕЛИ ДЕТЕЙ, РОЖДЕННЫХ ОТ МАТЕРЕЙ С ГЕСТАЦИОННЫМ САХАРНЫМ ДИАБЕТОМ, ОБУСЛОВЛЕННЫМ МУТАЦИЯМИ В ГЕНЕ ГЛЮКОКИНАЗЫ

() Н.А. Зубкова', Ф.Ф. Бурумкулова², В.А. Петрухин ${ }^{2}$, М.А. Плеханова², А.Е. Панов², В.И. Улятовская ${ }^{2}$, Т.С. Будыкина², Н.А. Макрецкая ${ }^{1}$, А.Н. Тюльпаков ${ }^{1}$

'ФГБУ Национальный медицинский исследовательский центр эндокринологии Минздрава России, Москва гГБУЗ МО Московский областной НИИ акушерства и гинекологии, Москва

ОБОСНОВАНИЕ. Гестационный сахарный диабет (ГСД), обусловленный мутациями в гене глюкокиназы (GCK), является наиболее частой моногенной формой диабета, дебютирующей во время беременности. В отличие от остальных моногенных форм, назначение инсулинотерапии беременным с мутациями в гене GCK должно базироваться на генотипе плода, который до рождения, как правило, неизвестен. В настоящем исследовании мы оценили влияние инсулинотерапии на показатели веса и роста детей при рождении в зависимости от наличия или отсутствия у них аналогичной мутации.

ЦЕЛЬ. Изучить особенности весо-ростовых показателей детей, рожденных от матерей с ГСД, обусловленным мутациями в гене глюкокиназы, в зависимости от терапии.

МЕТОДЫ. В исследование было включено 38 пациенток с ГСД, обусловленным мутациями в гене GCK, и 45 их детей. Молекулярно-генетическое исследование беременных проведено с помощью метода высокоэффективного параллельного секвенирования (панель «Сахарный диабет»). Поиск аналогичных мутаций у детей проводился методом прямого секвенирования Сэнгера. Пациентки были разделены на 3 группы в зависимости от генотипа детей и получаемой во время беременности терапии. Проводилось сравнение весо-ростовых показателей детей при рождении с последующей оценкой влияния на них инсулинотерапии.

РЕЗУЛЬТАТЫ. Мы Выявили статистически значимые отличия показателей роста $(p=0,04)$ и веса $(p=0,031)$ новорожденных детей в зависимости от генотипа ребенка и терапии матери. Показано, что риску развития макросомии подвержены младенцы, не унаследовавшие материнскую мутацию. Получено достоверное снижение показателей веса у детей с мутациями в гене GCK, чьи матери получали инсулинотерапию во время беременности. Однако оно укладывается в диапазон допустимых значений и не опосредует риски, связанные с гипотрофией новорожденного.

ЗАКЛЮЧЕНИЕ. При отсутствии возможности проведения пренатального молекулярно-генетического исследования назначение инсулинотерапии пациенткам с ГСД, обусловленным мутациями в гене GCK, способно предотвратить развитие макросомии у ребенка без аналогичной мутации и не приводит к патологическому снижению массы тела новорожденного, унаследовавшего материнскую мутацию. Важно придерживаться более мягкой тактики в достижении целевых показателей гликемии в отличие от пациенток с ГСД, обусловленным иными причинами.

КЛЮЧЕВЫЕ СЛОВА: гестационный сахарный диабет; глюкокиназа; макросомия; инсулинотерапия

\title{
BIRTH WEIGHT AND LENGTH IN OFFSPRINGS OF MOTHERS WITH GESTATIONAL DIABETES MELLITUS DUE TO MUTATIONS IN GCK GENE
}

(c) Natalia A. Zubkova', Fatima F. Burumkulova², Vasiliy A. Petrukhin², Margarita A. Plechanova², Anton E. Panov², Tatiana S. Budyikina², Victoria I. Ulyatovskaya ${ }^{2}$, Nina A. Makretskaya' ${ }^{1}$, Anatoly N. Tiulpakov ${ }^{1}$

'Endocrinology Research Centre, Moscow, Russia

${ }^{2}$ Moscow Regional Research Institute of Obstetrics and Gynecology, Moscow, Russia

BACKGROUND. Gestational diabetes (GDM) due to GCK gene mutations is the most frequent form of monogenic diabetes mellitus (DM) presenting during pregnancy. It has been suggested that the use of insulin in pregnancies with fetuses carrying GCK mutations may lead to intrauterine growth retardation. In the present study we evaluated the effect of insulin therapy during pregnancy on birth weight and length in the offsprings of mothers with GDM due to GCK mutations.

AIMS. The aim was to study birth weight and length in offsprings of mothers with gestational diabetes mellitus due to mutations in GCK, depending on the therapy during pregnancy.

MATERIALS AND METHODS. The study included 38 patients with GDM caused by GCK gene mutations (18.7\%) and the 45 offsprings. To define molecular basis of GDM in pregnant women we used a targeted NGS. 'Diabetes panel' genes were 
sequenced using a custom lon Ampliseq gene panel and PGM semiconductor sequencer (Ion Torrent). To found the same mutations in their offsprings was used Sanger sequencing. All children were divided into 3 groups depending of their genotype and therapy received by the mothers during pregnancy.

RESULTS. We found statistically significant differences in birth length $(p=0.04)$ and weight $(p=0,031)$ depending on the genotype of the child and therapy in the mother. The risk of macrosomia was shown in non-mutation-carrying offsprings only. The birth weight in children with GCK gene mutations whose mothers received insulin during pregnancy was significantly lower. However, the birth weight remained in the normal range.

CONCLUSIONS. Since prenatal diagnostics in the mothers with GCK gene mutations is not always justified, we recommend insulin therapy in order to prevent fetal macrosomia, which, however, should be less aggressive than in GDM due to other causes.

KEYWORDS: gestational diabetes mellitus; glucokinase; macrosomia; insulin therapy

Структура сахарного диабета у беременных представлена сахарным диабетом 1 (СД1) и 2 (СД2) типов, гестационным сахарным диабетом (ГСД) и моногенными формами $[1,2]$. К последним относятся доминантно наследуемые варианты заболевания, обусловленные дефектами одного из генов, регулирующих функцию бета-клеток, среди которых, прежде всего, выделяют подтипы MODY (Maturity-Onset Diabetes of the Young, диабет зрелого типа у молодых) [3]. Генетический дефект, обуславливающий гипергликемию, играет решающую роль в детерминировании размера плода у пациенток c MODY [4].

Инактивирующие гетерозиготные мутации в гене глюкокиназы (GCK) приводят к развитию сахарного диабета типа MODY2 - доброкачественной гипергликемии с ранним началом и высокой пенетрантностью [5]. В настоящее время MODY2 широко изучен и признан одним из наиболее распространенных подтипов моногенного диабета в мире [6]. Кроме того, именно MODY2 ассоциирован с развитием ГСД [7]. Около 10\% всех случаев ГСД обусловлены дефицитом глюкокиназы [8]. Согласно полученным нами данным, мутации в гене $G C K$ встречались у $18,7 \%$ (38/203) пациенток с ГСД [9]. Дифференцировать дефицит глюкокиназы у пациентов с ГСД чрезвычайно важно, поскольку только при данном дефекте риск макросомии и фетопатии опосредует не материнская гипергликемия, а генотип плода.

Потомство матерей GCK/ГСД является идеальной моделью для изучения влияния умеренной гипергликемии in utero, которая отличается от СД1 или СД2 значительно меньшей вариабельностью и небольшим ответом на инсулинотерапию. При этом развитие макросомии характерно только для младенцев, не имеющих мутации в гене $G C K$, они подвержены влиянию материнской гипергликемии, и их вес в среднем превышает на 700 г среднестатистический вес при рождении [10]. Дети, которые наследуют мутацию, имеют тот же гомеостатический уровень глюкозы, что и их матери, и ощущают более высокий уровень глюкозы как нормальный. Поэтому незначительная гипергликемия в этом случае не оказывает негативного влияния на вес ребенка, а применение инсулина для лечения GCK/ГСД выделяют как отдельный фактор риска рождения маловесного ребенка [11].

Несмотря на большое количество исследований, посвященных изучению ГСД, обусловленного мутациями в гене GCK, особенности весо-ростовых показателей плода в зависимости от его генотипа, как правило, носят ретроспективный характер, проведены на небольших выборках и нередко представляют собой описание отдельных клинических случаев $[12,13]$. Кроме того, в существующих исследованиях практически нет данных о влиянии сахароснижающей терапии, получаемой матерью с $G C K / Г C Д$, на весо-ростовые показатели плода в зависимости от его генотипа.

\section{ЦЕЛЬ}

Оценить влияние инсулинотерапии на весо-ростовые показатели детей, рожденных от матерей, беременность которых протекала на фоне ГСД, обусловленного мутациями в гене $G C K$, в зависимости от наличия или отсутствия у ребенка аналогичной мутации.

\section{МЕТОДЫ}

\section{Дизайн исследования}

На основании результатов молекулярно-генетического исследования женщин, чья беременность протекала на фоне ГСД, выделить группу пациенток с ГСД, обусловленным мутациями в гене GCK. Провести поиск аналогичных материнским мутаций всем новорожденным, а также детям от предыдущих беременностей, также протекавших на фоне ГСД. Провести сравнение весо-ростовых показателей в группах с целью оценки влияния проводимой терапии в зависимости от генотипа ребенка.

\section{Критерии соответствия}

В исследование были включены 203 пациентки с ГСД и отрицательным титром аутоантител (ICA, IA2, IA, GAD). ГCД диагностирован согласно рекомендациям Российского национального консенсуса «Гестационный сахарный диабет: диагностика, лечение и послеродовое наблюдение» [14].

\section{Условия проведения}

Настоящее исследование инициировано в рамках гранта Российского научного фонда №16-15-10408. Клиническое обследование пациенток проведено на базе ГБУЗ МО Московский областной НИИ акушерства и гинекологии (МОНИИАГ; директор - проф. Петрухин В.А.). Молекулярно-генетический анализ проводился в лаборатории отделения наследственных эндокринопатий ФГБУ «НМИЦ эндокринологии» Минздрава России (зав. отд., д.м.н. Тюльпаков А.Н.).

Продолжительность исследования

2016-2017 гг. 


\section{Описание медицинского участия}

Суточный мониторинг гликемии проводился беременными амбулаторно с использованием персональных глюкометров и занесением показателей гликемии в дневник самоконтроля. Инсулинотерапия назначалась в случае неэффективности диетотерапии в базисно-болюсном режиме. Согласно рекомендациям национального руководства «Неонатология», беременность считалась доношенной на сроке 37-42 нед [15]. Оценка весо-ростовых показателей новорожденных проводилась сразу после рождения с расчетом величины стандартного отклонения (SDS) показателей роста и веса для срока гестации с использованием программы «Auxology» (Pfizer). Задержка внутриутробного развития (или «малый для гестационного возраста») устанавливалась при снижении массы тела и роста при рождении ниже 10 перцентили для гестационного возраста. Масса тела при рождении менее 2500 г у новорожденного любого срока гестации считалась низкой (гипотрофия). Диагноз «Диабетическая фетопатия» (ДФП) устанавливался на основании: увеличения массы тела при рождении выше 2 SD в сочетании с признаками диспропорционального развития (увеличение размеров паренхиматозных органов, короткая шея и относительно короткие конечности, маленькая голова, широкий плечевой пояс, толстая шейная складка), утолщения и отека подкожно-жирового слоя, признаков неонатальной гипогликемии.

С целью проведения молекулярно-генетического исследования (МГИ) проводился забор венозной крови в момент установления диагноза ГСД. Геномную ДНК выделяли из лейкоцитов периферический крови стандартным методом (набор Pure Link, Genomic DNA Mini Kit, Life Technologies, США). Для молекулярно-генетического анализа матерям применялся метод высокопроизводительного параллельного секвенирования (NGS). Использовалась разработанная в отделении наследственных эндокринопатий ФГБУ «НМИЦ эндокринологии» панель праймеров для мультиплексной ПЦР и секвенирования с применением технологии Ion Ampliseq ${ }^{\text {TM }}$ Custom DNA Panel (Life Technologies, США). Секвенирование осуществлялось на полупроводниковом секвенаторе PGM (lon Torrent, Life Technologies, США). Биоинформатическая обработка результатов секвенирования проводилась с помощью программного модуля Torrent Suite 4.2.1 (Ion Torrent, Life Technologies, США) и пакета программ
Annovar (версия 2014Nov12). Интерпретация результатов исследований и оценка патогенности нуклеотидных изменений проводились согласно международным рекомендациям [16]. В последующем новорожденным детям проводился поиск аналогичных материнским мутаций на секвенаторе Genetic Analyzer Model 3130 (Life Technologies, США) [17].

\section{Анализ в группах}

В группу окончательного анализа было включено 38 пациентов с ГСД, обусловленным мутациями в гене $G C K$, и 45 детей (от 36 текущих беременностей и 9 предыдущих беременностей). Проанализирован исход 41 беременности, протекавшей на фоне ГСД, обусловленного гетерозиготными мутациями в гене GCK. В зависимости от наличия или отсутствия у ребенка (P) мутации в гене $G C K(\mathrm{P}+$ и $\mathrm{P}$ - соответственно) и терапии, получаемой матерью (М) во время беременности (М+/Инсулинотерапия, М+/Диетотерапия), были сформированы 3 группы пациентов.

Группа 1: М+/P+/Инсулинотерапия (Мать GCK+/Ребенок GCK+/Инсулинотерапия): 22 младенца с мутацией в гене $G C K$, матери которых получали инсулинотерапию.

Группа 2: М+/P+/Диетотерапия (Мать GCK+/Ребенок $G C K+/$ Диетотерапия): 7 детей с мутацией в гене GCK от матерей с аналогичной мутацией, лечение которых заключалось в соблюдении диеты.

Группа 3: М+/P-/Инсулинотерапия (Мать GCK+/Peбенок здоров/Инсулинотерапия): 16 новорожденных, не унаследовавших материнскую мутацию, чьи матери во время беременности получали инсулинотерапию.

Методы регистрации исходов: данные наблюдения за течением беременности, показатели гликемии, дозы инсулина, результаты МГИ, показатели веса и роста новорожденных были занесены в базы данных, сформированные с учетом цели исследования. С целью оценки весо-ростовых показателей детей от предыдущих беременностей, протекавших на фоне ГСД, было проведено дополнительное анкетирование матерей.

\section{Этическая экспертиза}

Данное исследование одобрено локальным этическим комитетом ГБУЗ МО МОНИИАГ (протокол №88 от 30/06/2016). Информированное согласие было подписано всеми обследованными пациентками, в том числе и на обследование их детей.

Таблица 1. Клиническая характеристика пациентов по группам (указаны Mediana [Q25;Q75])

\begin{tabular}{lccc}
\hline & Группа 1 (n=22) & Группа 2 (n=7) & Группа 3 (n=16) \\
\hline Пол, мал./дев. & $10 / 12$ & $5 / 2$ & $10 / 6$ \\
Срок гестации, нед* & $38,7 \pm 1,2$ & $39 \pm 1,2$ & $37,7 \pm 2,2$ \\
Вес, г & $3125[2800 ; 3300]$ & $3540[3290 ; 3670]$ & $3550[2930 ; 3890]$ \\
SDS веса & $-0,51[-1,17 ; 0,17]$ & $0,44[0,21 ; 0,7]$ & $0,66[0,48 ; 1,92]$ \\
Poст, см & $50[48 ; 51]$ & $53[52 ; 54]$ & $52[49 ; 53]$ \\
SDS роста & $0,4[0,16 ; 1,01]$ & $1,2[0,7 ; 2,3]$ & $0,7[-0,04 ; 2,1]$ \\
Среднесуточная гликемия, ммоль/л & $6,3[2,1 ; 11,3]$ & - & $6,18[2,7 ; 12]$ \\
Инициация инсулинотерапии, нед & $12,5[1 ; 30]$ & - & $14,5[5 ; 34]$ \\
Доза инсулина, Ед/кг & $1,2[0,8 ; 1,4]$ & & $0,7[0,5 ; 0,8]$ \\
\hline
\end{tabular}

* указаны M \pm SD 


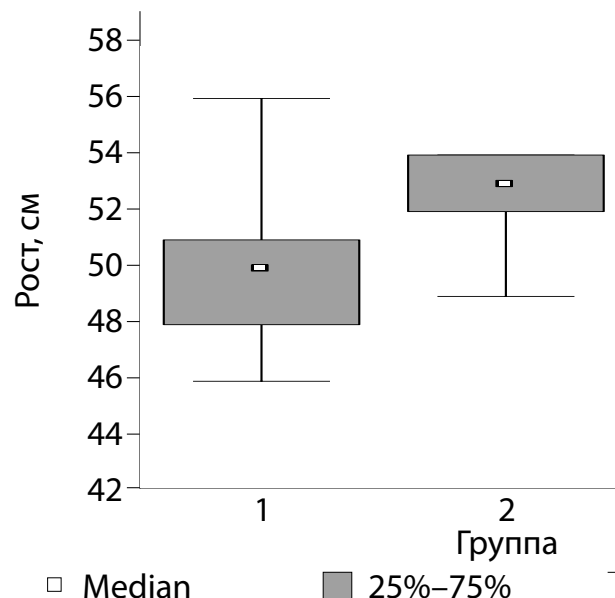

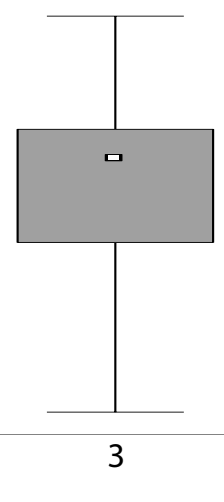

I Min-Max

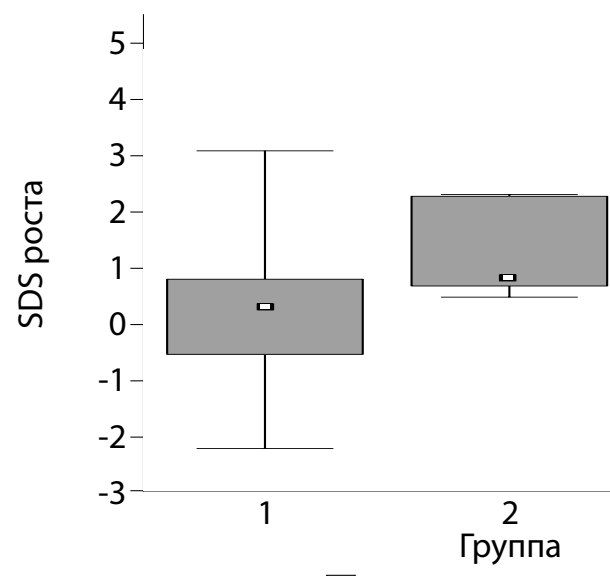

$\square$ Median $\square$ 25\%-75\% I Min-Max

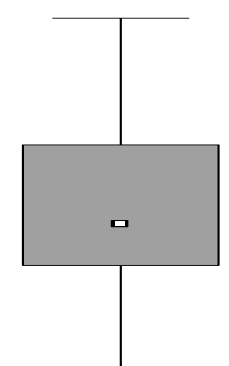

3

Рис. 1. Показатели роста и SDS роста новорожденных детей.

\section{Статистическая обработка}

Статистическая обработка материала проводилась с использованием программ Microsoft Office Excel 2010 и Statistica 6.0. Достоверность различий определяли, используя критерий Манна-Уитни. Различия считали достоверными при $\mathrm{p}<0,05$. Проводили дисперсионный анализ Краскелла-Уоллиса, а также корреляционный анализ с вычислением коэффициента Спирмена (R) и Гамма (G). Данные представлены как медиана (нижний квартиль; верхний квартиль).

\section{РЕЗУЛЬТАТЫ}

\section{Объекты (участники) исследования}

Мутации в гене GCK были выявлены у 18,7\% (38/203) пациентов с ГСД. Средний возраст обследуемых пациентов составил 27,0 лет [24,0;30,0]. Медиана срока гестации на момент диагностики ГСД составила 9 нед [7;20]. Срок родоразрешения колебался от 31 до 42 нед и статистически не отличался в группах $(p=0,21)$, составляя

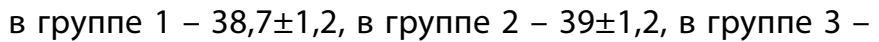
$37,7 \pm 2,2$ нед. В двух случаях отмечались преждевременные роды на 36-й неделе (группа 1) и на 31-й неделе (группа 3).

Методом Сэнгера проведен поиск аналогичных мутаций у 45 детей (от 36 текущих беременностей и 9 предыдущих беременностей). В результаты были сформированы 3 группы: в группу 1 вошли 22 ребенка (10 мальчиков и 12 девочек) с мутациями в гене GCK, чьи матери получали во время беременности инсулинотерапию. В группу 2

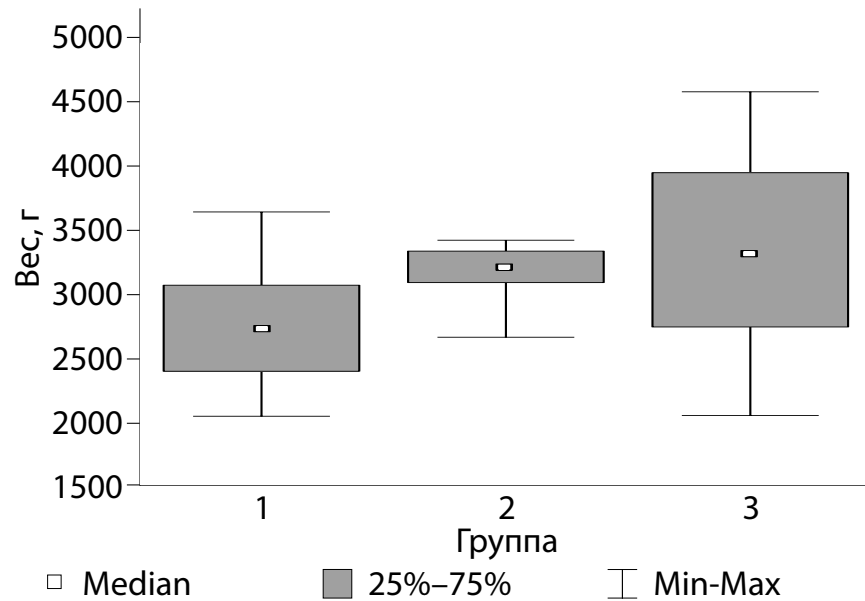

вошли 7 детей (5 мальчиков и 2 девочек) с мутациями в гене GCK, чьи матери находились во время беременности на диетотерапии. Группу 3 составили 16 детей (10 мальчиков и 6 девочек) без мутаций в гене GCK. Все матери детей группы 3 получали инсулинотерапию во время беременности. Срок инициации инсулинотерапии и показатели гликемии в группах 1 и 3 достоверно не отличались. Клиническая характеристика пациентов представлена в табл. 1.

\section{Основные результаты исследования}

Дисперсионный анализ Краскелла-Уоллиса выявил наличие статистически значимых отличий по показателям роста $(p=0,04)$ и веса $(p=0,031)$ новорожденных детей в группах.

В 1-й группе рост новорожденных детей колебался от 46 до 56 см. Медиана роста составила 50 см [48;51], а коэффициент стандартного отклонения - от -2,2 до 2,3 (Ме $0,44[0,16 ; 1,01])$. Только у одного ребенка SDS роста был более -2 SD (при SDS веса -1,44), что было обусловлено фетоплацентарной недостаточностью. В группе 2 рост детей входил в диапазон от 49 до 54 см (Mе 53 [52;54]) и был достоверно выше $(p=0,013)$ по сравнению с детьми группы 1. Коэффициент стандартного отклонения варьировал от 0,5 до 2,3 SD (Mе 1,2 [0,7;2,3]). В группе 3 рост детей находился в интервале от 43 до 57 см (Ме 52 [49;53]) и достоверно не отличался от показателей в 1-й $(p=0,15)$ и 2-й $(p=0,32)$ группах. Коэффициент стандартного отклонения колебался от -1,89 до 4,37 SD (Me 0,7 [-0,04;2,1]) (рис. 1).

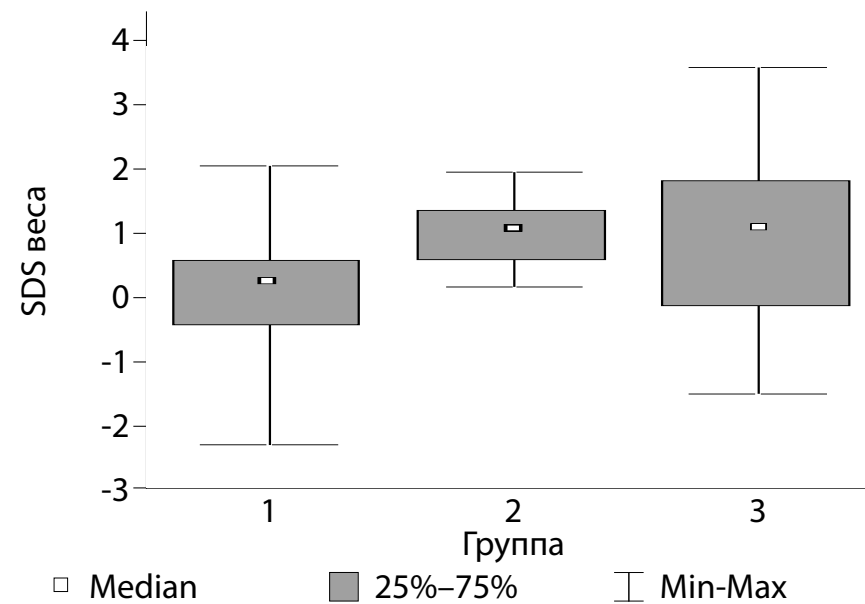

Рис. 2. Показатели веса и SDS веса новорожденных детей. 


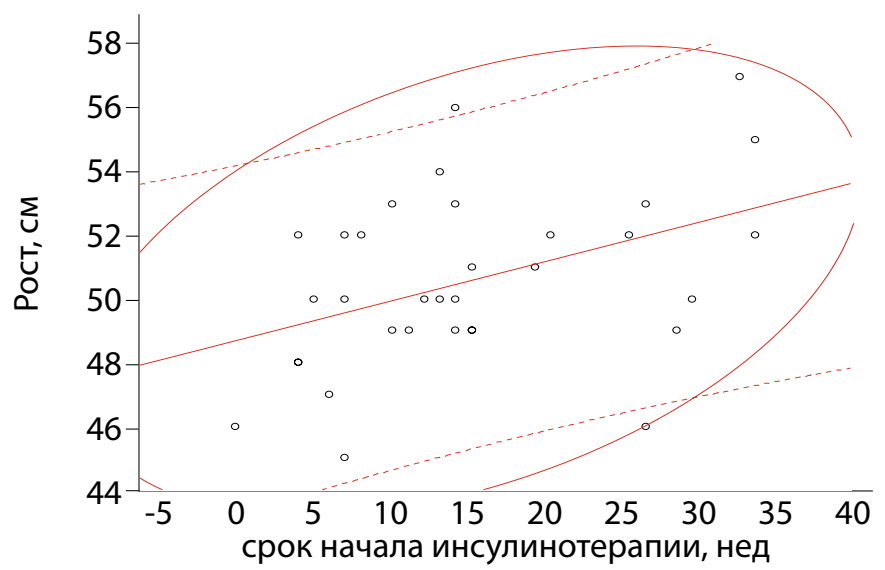

срок: рост: $r=0,4251, p=0,0137$

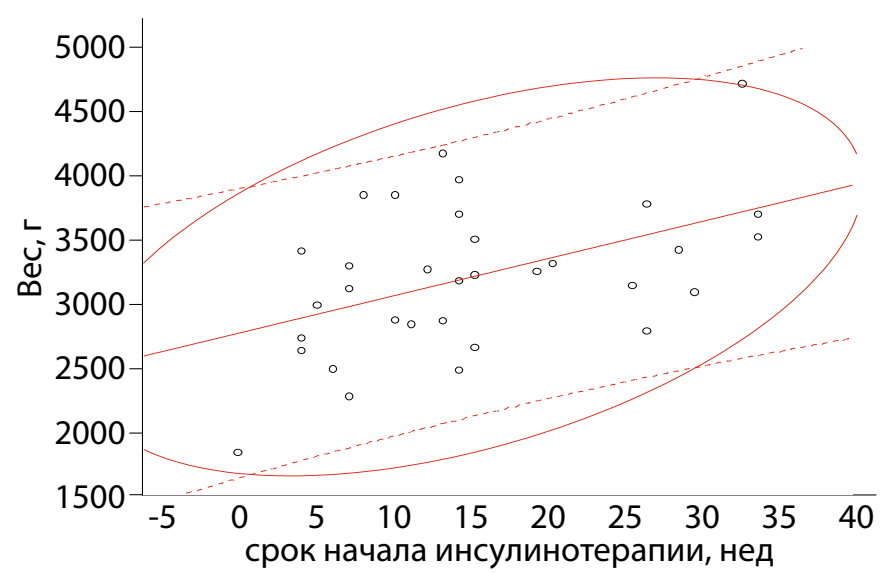

срок: вес: $r=0,4711, p=0,0057$

Рис. 3. Взаимосвязь весо-ростовых показателей новорожденных детей и срока начала инсулинотерапии у беременных с GCК/ГСД.

Вес новорожденных детей группы 1 колебался от 2560 до 3960 г (Ме 3125 [2800;3300]). Коэффициент стандартного отклонения варьировал от -1,79 до 0,87 SD (Ме -0,51 [-1,17;0,17]). В одном случае преждевременных родов на 36-й неделе показатель SDS веса составил -1,9 SD при SDS роста -0,5 SD. Инсулинотерапия у данной пациентки была инициирована еще на этапе планирования беременности (максимальная доза в III триместре 1,1 Ед/кг). Однако показатели гликемии не достигали целевых значений (натощак до 8,3 ммоль/л, через 1 ч после еды до 10,0 ммоль/л) на протяжении всей беременности. Вес новорожденных детей группы 2 колебался от 3100 до 3950 г (Ме 3540 [3290;3670]) и был достоверно выше, чем в группе 1 $(p=0,02)$. Коэффициент стандартного отклонения варьировал от 0,5 до 2,3 (Ме 0,44 [0,21;0,7]). Вес новорожденных детей группы 3 находился в пределах от 2310 до 4730 г (Ме 3550 [2930;3890], а коэффициент стандартного отклонения от -1,9 до 3,2 SD (Mе 0,66 [0,48;1,92]) у трех детей $(18,8 \%)$ превышал 2 SD. Достоверное отличие между показателями веса детей выявлено у пациентов групп 1 и 3 ( $p=0,036)$. Признаки диабетической фетопатии отмечались у 6 (37,5\%) новорожденных, в том числе у одного ребенка, родившегося на 31-й неделе гестации (SDS веса $+2,3$ ) (рис. 2).

\section{Нежелательные явления}

В данном исследовании нами не были отмечены нежелательные явления.

\section{ОБСУЖДЕНИЕ}

\section{Резюме основного результата исследования}

Мы провели сравнительный анализ весо-ростовых показателей новорожденных, рожденных от матерей, беременность которых протекала на фоне ГСД, обусловленного мутациями в гене GCK, в зависимости от наличия или отсутствия аналогичной мутации у ребенка и получаемой во время беременности терапии. Выявлено, что риск развития макросомии выше у детей, не унаследовавших аналогичную материнскую мутацию. У детей с мутациями в гене GCK отмечалось снижение весо-ростовых показателей на фоне инсулинотерапии у матери во время беременности.

\section{Обсуждение основного результата исследования}

В ходе проведенного нами исследования среди пациентов 1-й и 2-й групп выявлена корреляционная связь показателей веса $(G=0,61, p=0,0058)$ и роста $(G=0,69$, $\mathrm{p}=0,0019)$ от получаемой во время беременности терапии (диета/инсулин). Вес новорожденных был достоверно выше у детей, чьи матери находились на диетотерапии.

У новорожденных детей, рожденных от женщин, получавших терапию инсулином во время беременности, выявлена корреляционная связь между сроком начала инсулинотерапии и показателями роста и веса плода. Инсулинотерапия была инициирована на сроках от 1 до 34 нед беременности.

Данная взаимосвязь выражена в большей степени у детей с мутациями в гене GCK по сравнению с детьми без мутаций. При этом вес детей, не унаследовавших материнскую мутацию (М+/P-), был больше веса детей с мутацией $(\mathrm{G}=0,41, \mathrm{p}=0,01)$. Стоит отметить, что более раннее начало инсулинотерапии ассоциировано с нормализацией веса у детей без мутаций и редуцированием веса у детей с мутациями (рис. 3).

Тенденция к малому весу детей при рождении выявлена у 3 новорожденных группы 1: у одной пациентки с поздним началом инсулинотерапии (22 нед) и низкой комплаентностью (рост -1,3 SD/вес -1,4 SD) данная задержка была симметричной и опосредована фетоплацентарной недостаточностью. В двух других случаях дефицит веса преобладал над дефицитом роста (рост -1,3 SD/вес -1,8 SD; рост -0,5 SD/вес -1,4 SD). Инсулинотерапия (в III триместре до 1,1-1,4 Ед/кг) в этих случаях была начата рано (в 5 и 7 нед), с достижением жестких целевых показателей гликемии (натощак до 5,1, после еды до 7,0 ммоль/л) и эпизодами гипогликемий. В случаях, когда инсулинотерапия не носила агрессивного характера, и показатели гликемии варьировали в более широком диапазоне (после еды до 12,4 ммоль/л), редуцирования весо-ростовых показателей не выявлено. Стоит отметить, что для пациенток с GCK/ГСД, вынашивающих ребенка с аналогичной мутацией, характерны высокая вариабельность гликемии и трудности в достижении целевых показателей гликемии, несмотря на использование больших доз инсулина.

В группе 3 получен высокий процент (37,5\%) детей, рожденных с признаками диабетической фетопатии. В половине случаев диабетическая фетопатия опосредована поздним началом инсулинотерапии (после 29-й недели), в остальных - низкой комплаентностью пациенток. При этом для достижения целевых показателей глике- 
мии им требовались меньшие дозы инсулина, чем пациенткам, чьи дети унаследовали аналогичную мутацию.

Таким образом, данное исследование показало, что риску развития макросомии подвержены только младенцы, не унаследовавшие материнскую мутацию. Полученные нами результаты исследования согласуются с данными ряда зарубежных авторов $[10,11,18]$. Согласно данным литературы, если мать и ребенок имеют мутации в гене GCK, эффекты отменяют друг друга, и ребенок имеет нормальный вес при рождении. Существует единичное описание клинических случаев, демонстрирующих редуцирование веса при рождении в случае использования инсулинотерапии у пациенток с GCK/ГСД, которое, вероятнее всего, было обусловлено агрессивным снижением материнской гипергликемии [19]. В нашем исследовании была выявлена тенденция к снижению весо-ростовых показателей у детей с мутацией в гене GCK, чьи матери получали инсулинотерапию во время беременности. Однако снижение показателей веса не было критичным и укладывалось в диапазон нормальных антропометрических показателей для новорожденных.

\section{Ограничения исследования}

Основным ограничением нашего исследования являлась малая численность пациенток группы 2 (т.е. не получавших инсулинотерапию во время беременности). Все пациенты данной группы были рождены от предыдущих беременностей, которые также протекали на фоне ГСД.

\section{ЗАКЛЮЧЕНИЕ}

Вероятно, «золотым стандартом» в выборе тактики лечения диабета беременных, обусловленного мутациями в гене GCK, могло бы стать пренатальное определение генотипа плода. Однако, учитывая сопряженные с этим риски и отсутствие выраженного негативного влияния инсулинотерапии на параметры веса и роста при рождении, обосновать применение данной методики достаточно трудно. Расширение диапазона целевой гликемии у пациенток с GCK/ГСД поможет избежать редуцирования веса у детей с аналогичной мутацией, но при этом не приведет к развитию макросомии у детей, не унаследовавших мутацию.

\section{ДОПОЛНИТЕЛЬНАЯ ИНФОРМАЦИЯ}

Финансирование исследование. Исследование выполнено при поддержке Российского научного фонда (проект №16-15-10408).

Конфликт интересов. Авторы декларируют отсутствие явных и потенциальных конфликтов интересов, связанных с публикацией настоящей статьи.

Участие авторов. Н.А. Зубкова - концепция и дизайн исследования, анализ полученных данных, написание текста; Н.А. Макрецкая, А.Н. Тюльпаков - проведение молекулярно-генетического исследования, концепция и дизайн исследования, анализ полученных данных, написание текста; Ф.Ф. Бурумкулова, М.А. Плеханова, В.И. Улятовская, A.Е. Панов - сбор материала, анализ полученных данных.

\section{СПИСОК ЛИТЕРАТУРЫ | REFERENCES}

1. Baz B, Riveline JP, Gautier JF. Endocrinology of pregnancy: Gestational diabetes mellitus: definition, aetiological and clinical aspects. Eur J Endocrinol. 2016;174(2):R43-51. doi: 10.1530/EJE-15-0378

2. Doddabelavangala Mruthyunjaya M, Chapla A, Hesarghatta Shyamasunder A, et al. Comprehensive Maturity Onset Diabetes of the Young (MODY) Gene Screening in Pregnant Women with Diabetes in India. PLoS One. 2017;12(1):e0168656. doi: 10.1371/journal. pone.0168656

3. Lachance $\mathrm{CH}$. Practical Aspects of Monogenic Diabetes: A Clinical Point of View. Can J Diabetes. 2016;40(5):368-375. doi: 10.1016/j.jcjd.2015.11.004

4. Lowe WL, Jr., Scholtens DM, Sandler V, Hayes MG. Genetics of Gestational Diabetes Mellitus and Maternal Metabolism. Curr Diab Rep. 2016;16(2):15. doi: 10.1007/s11892-015-0709-z

5. Wedrychowicz A, Tobor E, Wilk M, et al. Phenotype Heterogeneity in Glucokinase-Maturity-Onset Diabetes of the Young (GCK-MODY) Patients. J Clin Res Pediatr Endocrinol. 2017;9(3):246-252. doi: 10.4274/jcrpe. 4461

6. Pihoker C, Gilliam LK, Ellard S, et al. Prevalence, characteristics and clinical diagnosis of maturity onset diabetes of the young due to mutations in HNF1A, HNF4A, and glucokinase: results from the SEARCH for Diabetes in Youth. J Clin Endocrinol Metab. 2013;98(10):4055-4062. doi: 10.1210/jc.2013-1279

7. Shaat N, Karlsson E, Lernmark A, et al. Common variants in MODY genes increase the risk of gestational diabetes mellitus. Diabetologia. 2006;49(7):1545-1551. doi: 10.1007/s00125-006-0258-8

8. Colom C, Corcoy R. Maturity onset diabetes of the young and pregnancy. Best Pract Res Clin Endocrino/ Metab. 2010;24(4):605-615. doi: 10.1016/j.beem.2010.05.008

9. Zubkova N, Burumkulova F, Petrukhin V, et.al. High frequency of monogenic forms in gestational diabetes were demonstrated by targeted next generation sequencing. In: Proceedings of the $43^{\text {th }}$ Annual Meeting of the International Society for Pediatric and Adolescent Diabetes (ISPAD); 2017 Oct 18-21; Innsbruck.

10. Velho G, Hattersley AT, Froguel P. Maternal diabetes alters birth weight in glucokinase-deficient (MODY2) kindred but has no influ- ence on adult weight, height, insulin secretion or insulin sensitivity. Diabetologia. 2000;43(8):1060-1063. doi: 10.1007/s001250051490

11. Spyer G, Hattersley AT, Sykes JE, et al. Influence of maternal and fetal glucokinase mutations in gestational diabetes. Am J Obstet Gynecol. 2001;185(1):240-241. doi: 10.1067/mob.2001.113127

12. Chakera AJ, Steele AM, Gloyn AL, et al. Recognition and Management of Individuals With Hyperglycemia Because of a Heterozygous Glucokinase Mutation. Diabetes Care. 2015;38(7):1383-1392. doi: $10.2337 /$ dc $14-2769$

13. Stuebe AM, Wise A, Nguyen T, et al. Maternal genotype and gestational diabetes. Am J Perinatol. 2014;31(1):69-76. doi: 10.1055/s-0033-1334451

14. Дедов И.И., Краснопольский В.И., Сухих Г.Т. Российский национальный консенсус: «Гестационный сахарный диабет: диагностика, лечение, послеродовое наблюдение» // Сахарный диaбem. - 2012. - T. 15. - №4. - C. 4-10. [Dedov II, Krasnopol'skiy VI, Sukhikh GT. Russian National Consensus Statement on gestational diabetes: diagnostics, treatment and postnatal care. Diabetes mellitus. 2012;15(4):4-10. (In Russ.)] doi: 10.14341/2072-0351-5531

15. Володин Н.Н. Неонатология. Начиональное руководство. - М.; 2008. [Volodin NN. Neonatologiya. National guidelines. Moscow; 2008. (In Russ.)]

16. Richards S, Aziz N, Bale S, et al. Standards and guidelines for the interpretation of sequence variants: a joint consensus recommendation of the American College of Medical Genetics and Genomics and the Association for Molecular Pathology. Genet Med. 2015;17(5):405-424. doi: 10.1038/gim.2015.30

17. Зубкова Н.А., Гиоева О.А., Тихонович Ю.В., и др. Персонализация коррекции нарушений углеводного обмена с учетом генотипа у пациентов с сахарным диабетом типа MODY, обусловленного мутациями в генах GCK, HNF1A, HNF4A // World Journal of Personalized Medicine. - 2017. - T. 1. - №1. - C. 40-48. ZZubkova NA, Gioeva OA, Tikhonovich YV, et al. Genotype-based personalized correction of glycemic control in patients with MODY due to mutations in GCK, HNF1A AND HNF4A genes. World Journal of Personalized Medicine. 2017;1 (1):40-48. (In Russ.)] doi: 10.14341/wjpm9298 
18. Chakera AJ, Steele AM, Gloyn AL, et al. Recognition and Management of Individuals With Hyperglycemia Because of a Heterozygous Glucokinase Mutation. Diabetes Care. 2015;38(7):1383-1392. doi: 10.2337/dc14-2769
19. Hattersley AT, Beards F, Ballantyne E, et al. Mutations in the glucokinase gene of the fetus result in reduced birth weight. Nat Genet. 1998;19(3):268-270. doi: 10.1038/953

\section{ИНФОРМАЦИЯ ОБ АВТОРАХ [AUTHORS INFO]}

Зубкова Наталья Анатольевна, к.м.н., С.H.c. [Natalia A. Zubkova, MD, PhD, senior research associate]; адрес: 117036, Москва, ул. Дмитрия Ульянова, д.11 [address: 11 Dm. Ulyanova street, Moscow, 117036 Russian Federation]; ORCID: http://orcid.org/0000-0002-1346-7545; eLibrary SPIN: 5064-9992; e-mail: zunata2006@yandex.ru.

Тюльпаков Анатолий Николаевич, д.М.н. [Anatoly N. Tiulpakov, MD, PhD];

ORCID: http://orcid.org/0000-0001-8500-4841; eLibrary SPIN: 8396-1798; e-mail: ant@endocrincentr.ru

Бурумкулова Фатима Фархадовна, д.м.н., в.н.с. [Fatima F. Burumkulova, MD, PhD, leading research associate];

ORCID: http://orcid.org/0000-0001-9943-0964; eLibrary SPIN: 6592-7736; e-mail: fatima-burumkulova@yandex.ru

Петрухин Василий Алексеевич, д.м.н., профессор [Vasily A. Petrukhin, MD, PhD, Professor];

ORCID: http://orcid.org/0000-0003-0460-3047; eLibrary SPIN: 9236-6783; e-mail: petruhin271058@mail.ru

Плеханова Маргарита Александровна, врач-эндокринолог [Margarita A. Plechanova, MD];

ORCID: http://orcid.org/0000-0002-5322-1021; eLibrary SPIN: 8860-9060; e-mail: margarita_kr@list.ru

Улятовская Виктория Ивановна, врач акушер-гинеколог [Victoria I. Ulyatovskaya, MD]; eLibrary SPIN: 2988-9072;

ORCID: http://orcid.org/0000-0002-0930-3476; e-mail: 1akmoniiag@mail.ru

Будыкина Татьяна Сергеевна, д.м.н. [Tatiana S. Budykina, MD, PhD]; ORCID: http://orcid.org/0000-0001-9873-2354; eLibrary SPIN: 9952-8668; e-mail: budyt@mail.ru

Панов Антон Евгеньевич, н.c. [Anton E. Panov, MD, research associate]; ORCID: https://orcid.org/ 0000-0002-9362-0852; eLibrary SPIN: 9328-7938; e-mail: drpanov82@gmail.com

Макрецкая Нина Алексеевна, н.c. [Nina A. Makretskaya, MD, research associate];

ORCID: http://orcid.org/0000-0003-0412-7140; eLibrary SPIN: 4467-7880; e-mail: makretskayan@gmail.com

\section{ЦИТИРОВАТЬ:}

Зубкова Н.А., Бурумкулова Ф.Ф., Петрухин В.А., Плеханова М.А., Панов А.Е., Будыкина Т.С., Улятовская В.И., Макрецкая Н.А., Тюльпаков А.Н. Весо-ростовые показатели детей, рожденных от матерей с гестационным сахарным диабетом, обусловленным мутациями в гене глюкокиназы // Сахарный диабет. — 2018. — Т. 21. — №2. — С. 92-98. doi: 10.14341/DM9429

\section{TO CITE THIS ARTICLE:}

Zubkova NA, Burumkulova FF, Petrukhin VA, Plechanova MA, Panov AE, Budyikina TS, Ulyatovskaya VI, Makretskaya NA, Tiulpakov AN. Birth weight and length in offsprings of mothers with gestational diabetes mellitus due to mutations in GCK gene. Diabetes Mellitus. 2018;21(2):92-98. doi: 10.14341/DM9429 